\title{
Aplikasi Monitoring Wifi.Id PT Telekomunikasi Indonesia Berbasis Android
}

\author{
Riona Alpeni' ${ }^{1}$, Irawan Hadi², Sopian Soim ${ }^{3}$ \\ ${ }^{1}$ Program Studi Teknik Telekomunikasi, Politeknik Negeri Sriwijaya, Palembang, Indonesia \\ 1Rionaalpeni3@gmail.com, 2Irawanhadi@gmail.com, 33sopian_soim2005@yahoo.com
}

\begin{abstract}
The development of telecommunications network technology in Indonesia begins with wireline to become wireless telecommunications as it is today. One of the wireless telecommunications technologies used today is Wireles Fidelity (Wi-Fi) which has the advantage of being in terms of sending signals and having a high frequency. One of the Wireless Fidelity (WiFi) service providers, namely PT Telekomunikasi Indonesia with its products, named Wifi.Id. The amount of bandwidth in the Access Point (AP) always changes according to the number of users connected to the Access Point (AP). So that PT Telekomunikasi Indonesia needs to monitor the Access Point (AP) to meet user satisfaction. In addition to Bandwidth, other parameters are also checked on the Access Point (AP), namely Service Set Identifier (SSID), Media Access Control Address (MAC Address), Received Signal Strength Indication (RSSI), Data Rate, and Frequency Access Point (AP) which is measured in real time in the field. In this study the application was built using Android Studio which uses the Java programming language and XML, as well as for storing data using the MySQL database. The method used for building applications uses the Prototype method. The results of the research carried out are an android-based application for monitoring Access Points (AP) that can facilitate the operators of PT Telekomunikasi Indonesia.
\end{abstract}

Keywords: Monitoring, Wifi.id, Access Point (AP), Real Time, Android

\begin{abstract}
Abstrak
Perkembangan teknologi jaringan telekomunikasi di Indonesia diawali dengan telekomunikasi kabel (wireline) hingga menjadi telekomunikasi nirkabel (wireless) seperti sekarang ini. Salah satu teknologi telekomunikasi wireless yang digunakan saat ini adalah Wireles Fidelity (Wi-Fi) yang mempunyai keunggulan yaitu dalam hal pengiriman sinyal serta memiliki frekuensi yang tinggi. Salah satu penyedia layanan Wireless Fidelity (WiFi) yaitu PT Telekomunikasi Indonesia dengan produknya yang diberi nama Wifi.Id. Besar bandwidth pada Access Point (AP) selalu berubah sesuai dengan banyaknya pengguna yang terhubung pada Access Point (AP) tersebut. Sehingga PT Telekomunikasi Indonesia perlu melakukan monitoring pada Access Point (AP) untuk memenuhi kepuasan dari pengguna. Selain Bandwidth, dilakukan pengecekan juga parameter lainnya yang ada pada Access Point (AP) yaitu Service Set Identifier (SSID), Media Access Control Address (MAC Address), Received Signal Strength Indication (RSSI), Data Rate, dan Frekuensi Access Point (AP) yang diukur secara real time dilapangan. Pada penelitian ini aplikasi dibangun menggunakan Android Studio yagn menggunakan bahasa pemrograman Java dan XML, serta untuk penyimpanan data yangmenggunakan database MYSQL. Metode yang digunakan untuk pembangunan aplikasi emggunakan metode Prototype.
\end{abstract}

Kata kunci: Monitoring, Wifi.id, Access Point (AP), Real Time, Android 


\section{PENDAHULUAN}

Pesatnya perkembangan teknologi telekomunikasi baik dari sarana maupun prasarananya, mengharuskan pelayanan jasa dalam bidang telekomunikasi berkembang baik secara kualitas maupun kuantitasnya, agar dapat memenuhi kebutuhan dan kepuasan dari masyaratakat. Teknologi wireless merupakan teknologi di bidang telekomunikasi yang menawarkan kemudahan dibandingkan teknologi wired atau dengan media kabel [1]. Teknologi wireless memiliki kelebihan yaitu menawarkan kemudahan kepada pengguna, karena pengguna dapat berpindah-pindah tempat tanpa perlu menggunakan koneksi kabel selama masih berada dalam jangkauan sinyal wireless tersebut. Salah satu implementasi dari jaringan telekomunikasi teknologi wireless adalah adanya sistem Access Point (AP). Dengan adanyan sistem Access Point (AP) ini, pengguna dapat lebih mudah terhubung dengan jaringan Local Area Network (LAN) kabel secara wireless.

Wi-Fi (Wireless Fidelity) adalah sekumpulan standar yang digunakan untuk Jaringan Lokal Nirkabel Wireless Local Area Networks (WLAN) berdasarkan spesifikasi IEEE 802.11. Wi-Fi (Wireless Fidelity) merupakan koneksi tanpa kabel dengan mempergunakan teknologi radio sehingga pemakainya dapat mentransfer data dengan cepat dan aman. Layanan jaringan teknologi wireless yang disediakan salah satu penyedia jasa layanan telekomunikasi yaitu, PT Telekomunikasi Indonesisa adalah Wifi.id. PT Telekomunikasi Indonesia merupakan salah satu penyedia layanan jaringan teknologi wireless yang menggunakan standarisasi kerja di frekuensi 2,4 GHz dengan kecepatan sampai dengan $72 \mathrm{Mbps}$ dan frekuensi $5 \mathrm{GHz}$ Access Point (AP) dengan kecepatan sampai 300 Mbps[2].

Menurut Manager Marketing and Sales \& Customer Care PT Telekomunikasi Indonesia Divre 3 masih terdapat keluhan yang muncul dari kualitas layanan wifi.id yang ada [3]. Oleh karena itu operator PT Telekomunikasi Indonesia harus rutin melakukan pengecekan kualitas layan dari wifi.id yaitu dengan melakukan pengecekan pada Access point (AP) yang digunkan oleh pelanggan. Pengecekan dilakukan dengan memerika beberapa parameter yang ada pada Access Point (AP) seperti Bandwidth, Channel dan sebagainya. Namun pengecekan Access Point (AP) ini memerlukan banyak waktu, karena operator PT Telekomunikassi Indonesia harus melakukan pengecekan satu persatu parameter yang ada pada Access Point (AP) tersebut. Maka dari itu dari penelitian ini dibangun sebuah aplikasi berbasis android yang dapat mempermudah operator PT Telekomunikasi dalam melakukan pengecekan parameter pada Access Point (AP). Adapun parameter yang dapat di lakukan pengecekan pada aplikasi berbasis andorid ini yaitu berupa Bandwidth, Service Set Identifier (SSID), Media Access Control Address (MAC Address), Received Signal Strength Indication (RSSI), Data Rate, dan Frekuensi Access Point (AP).

\section{METODOLOGI PENELITIAN}

Metode pengembangan perangkat lunak yang digunakan pada penelitian ini yaitu menggunakan metode pengembangan prototype. Prototype merupakan metodologi pengembangan software yang menitikberatkan pada pendekatan aspek 
desain, fungsi dan user-interface. Developer dan user fokus pada user-interface dan bersama-sama mendefinisikan spesifikasi, fungsi, desain dan bagaimana software bekerja [5].

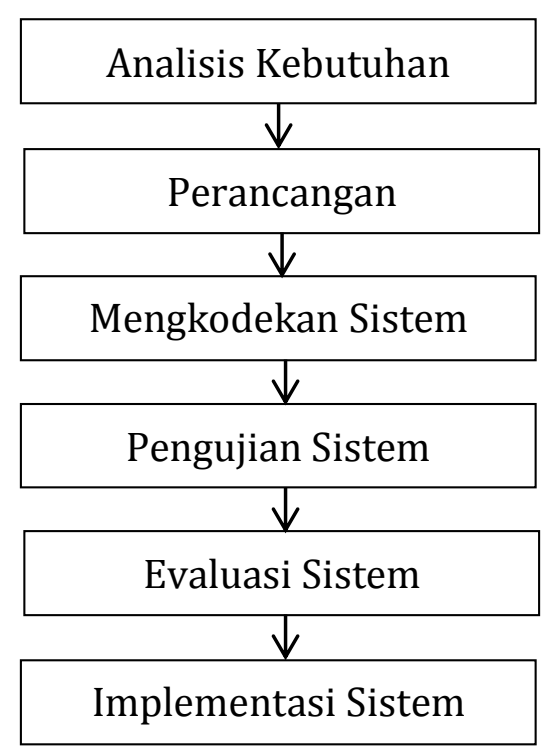

Gambar 1. Model Prototype

Metode Prototype memiliki 6 tahapan, yaitu :

a. Analisis kebutuhan

Pada tahap ini, dilakukan analisa kebutuhan pengguna, penentuan tujuan perancangan atau menentukan gambaran apa saja akan dibutuhkan kedepannya.

b. Perancangan

Perancangan ini dilakukan dengan cepat dan akan mewakili semua aspek suatu aplikasi, dan rancangan ini merupakani dasar dari pembuatan aplikasi.

c. Mengkodekan Sistem

Ini merupakan tahapan mengkodekan sistem menggunakan suatu aplikasi atau software yang sudah ditetapkan oleh pengembang dan dengan bahasa pemrograman yang sesuai.

d. Pengujian Sistem

Apabila sistem sudah menjadi perangkat lunak, akan dilakukan pengujian sebelum pengguna menggunakan perangkat lunak tersebut.

e. Evaluasi Sistem

Setelah dilakukan pengujian sistem, maka dilakukan evaluasi sistem tersebut, apakah sudah sesuai dengan kebutuhan dari pengguna.

f. Implementasi Sistem

Apabila perangkat lunak yang telah selesai diuji dan sudah sesuai dengan kebutuhan pengguna maka perangkat lunak siap untuk digunakan[6]. 


\section{HASIL DAN PEMBAHASAN}

\subsection{Hasil}

Hasil dari penelitian yang dibuat adalah berupa aplikasi monitoring Wifi.id berbasis android. Isi dari aplikasi tersebut berupa informasi mengenai parameterparameter yang ada pada Access Point (AP) seperti Bandwidth, Service Set Identifier (SSID), Media Access Control Address (MAC Address), Received Signal Strength Indication (RSSI), Data Rate, dan Frekuensi Access Point (AP). Sehingga dengan adanya aplikasi ini dapat memudahkan operator PT Telekomunikasi Indonesia dalam melakukan monitoring Access Point (AP).

\subsection{Pembahasan}

Aplikasi pada penelitian ini dibangun dengan menggunakan software android studio yang menggunakan bahasa pemrograman Java serta untuk membuat tampilan pada aplikasi menggunakan XML sedangkan untuk database digunakan web server yang menggunakan software Sublime Text dan menggunakan bahasa pemrograman PHP.

\section{a. Pembuatan Tampilan Aplikasi}

Pembuatan Aplikasi Monitoring Wifi.id PT Telekomunikasi Indonesia Berbasis Android menggunakan software Android Studio. Tampilan harus menggambarkan bagaimana aplikasi akan ditampilkan pada perangkat Android.

b. Pembuatan Coding Aplikasi

Pembuatan coding aplikasi merupakan tahapan dimana proses pengkodean agar aplikasi dapat dijalankan pada perangkat Android. Proses pengkodean (coding) aplikasi masih menggunakan software Android Studio dengan bahasa pemrograman Java.

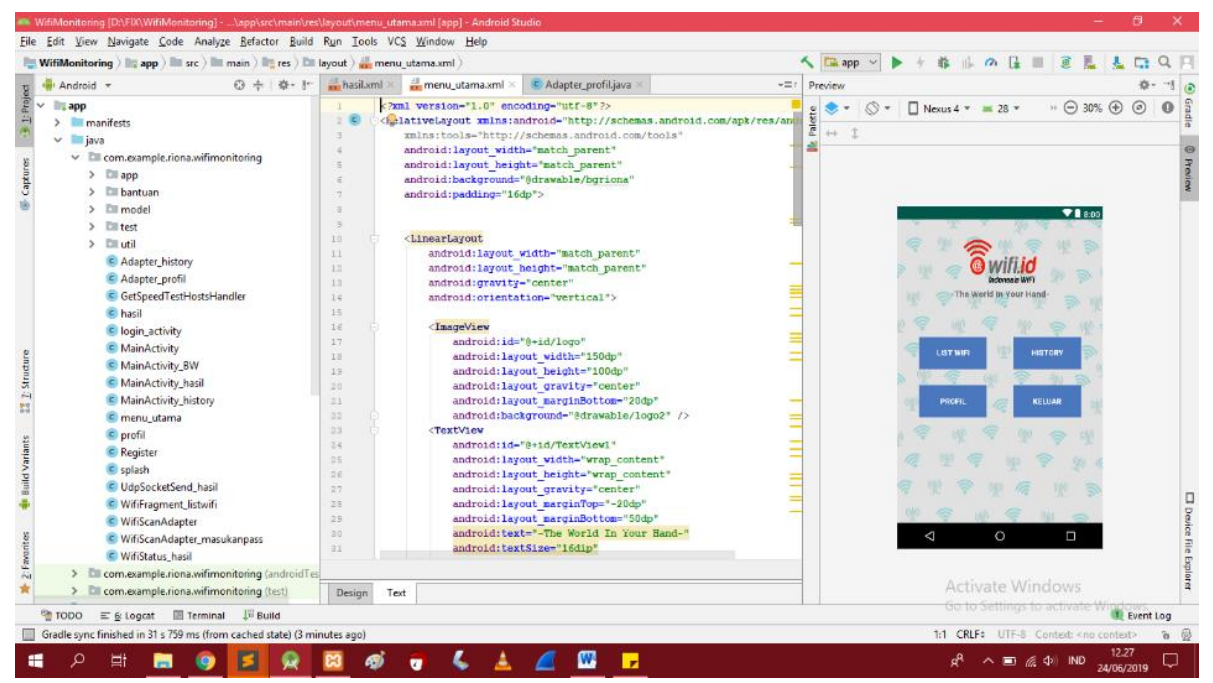

Gambar 2. Halaman Coding Aplikasi 


\section{c. Pembuatan Database}

Pembuatan database menggunakan software Sublime Text, pada software ini dirancang tampilan dan juga dilakukan pengkodean agar dapat dijalankannya database dari web server yang menggunakan bahasa pemrograman PHP.

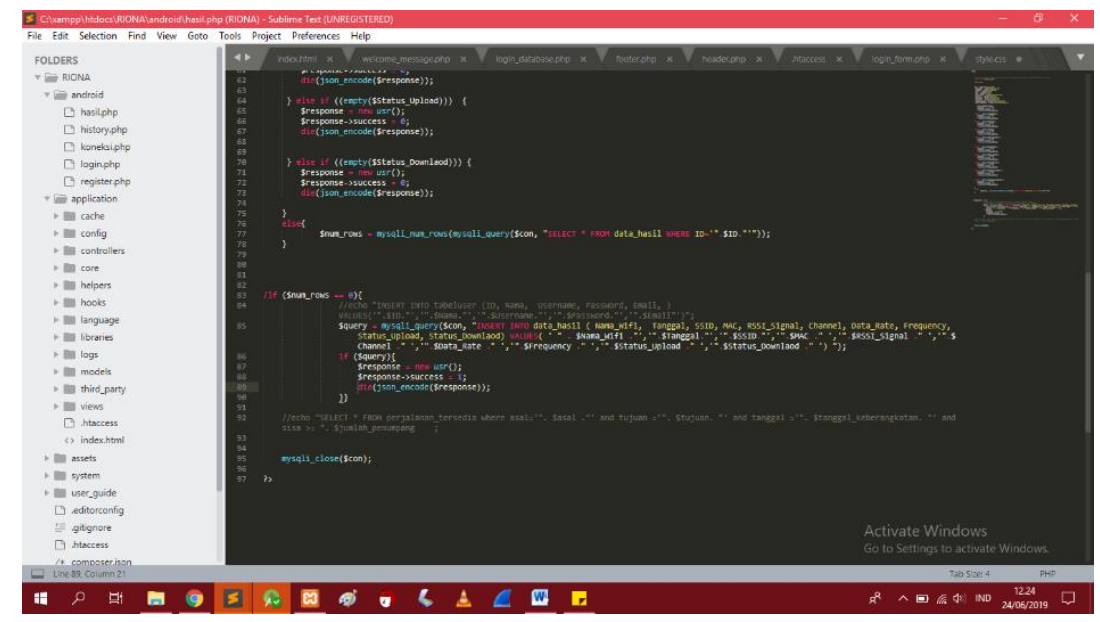

Gambar 3. Halaman Sublime Text

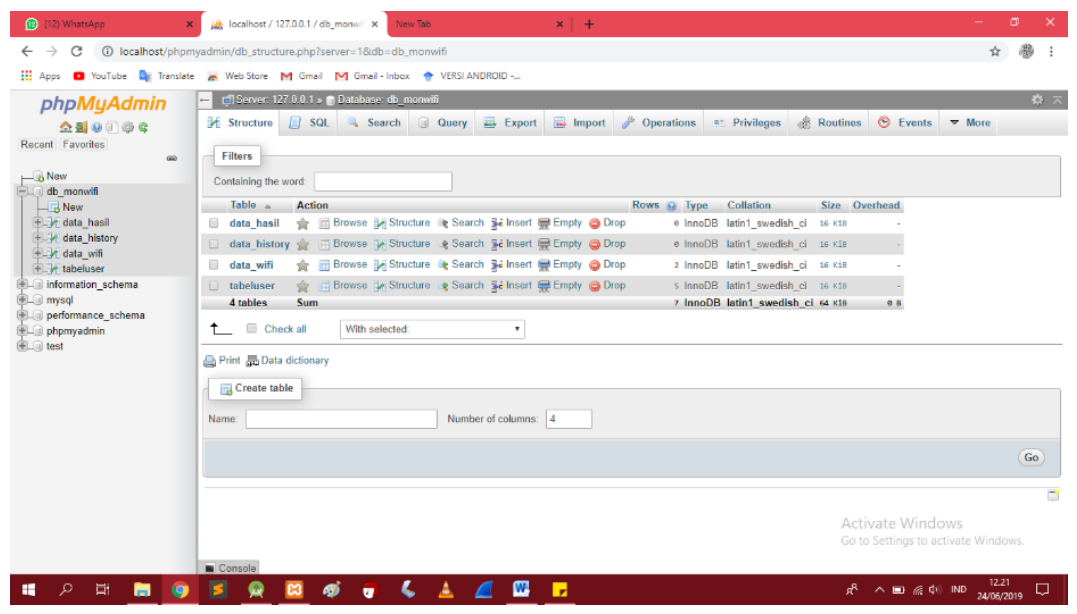

Gambar 4. Halaman Database

\subsection{Analisa}

Dari beberapa software yang digunakan tersebut, didapatkanlah sebuah aplikasi berbasis android. Setelah menjadi sebuah aplikasi dilakukanlah pengujian pada setiap halaman yang ada pada aplikasi untuk mengetahui kesesuaian antara sistem yang telah dirancang dengan fungsionalnya. Berikut ini tabel pengujiannya :

Tabel 1. Hasil Pengujian Fungsional Aplikasi

\begin{tabular}{|c|l|c|c|}
\hline \multirow{2}{*}{ No } & \multirow{2}{*}{ Halaman yang Diuji } & \multicolumn{2}{|c|}{ Hasil Pengujian } \\
\cline { 3 - 4 } & & Berhasil & Gagal \\
\hline 1. & Splash Screen & $\mathrm{v}$ & - \\
\hline 2. & Log in & $\mathrm{v}$ & - \\
\hline
\end{tabular}

Aplikasi Monitoring Wifi.Id PT Telekomunikasi Indonesia Berbasis Android (Riona Alpeni) | 175 


\begin{tabular}{|c|l|c|c|}
\hline No & \multirow{2}{*}{ Halaman yang Diuji } & \multicolumn{2}{|c|}{ Hasil Pengujian } \\
\cline { 3 - 4 } & & Berhasil & Gagal \\
\hline 3. & Register & $\mathrm{V}$ & - \\
\hline 4. & Menu Utama & $\mathrm{v}$ & - \\
\hline 5. & Scan Wifi & $\mathrm{v}$ & - \\
\hline 6. & Parameter wifi & $\mathrm{v}$ & - \\
\hline 7. & History & $\mathrm{v}$ & - \\
\hline 8. & Profil & $\mathrm{v}$ & - \\
\hline
\end{tabular}

Setelah pengujian selesai dilakukan maka aplikasi siap untuk digunakan digunakan oleh operator PT Telekomunikasi Indonesia untuk melalakukan monitoring parameter yang ada pada Access Point (AP).

\subsection{Implementasi}

Pada bagian implementasi ini menjelaskan bagaimana keluaran dari apklikasi yang telah dirancang.

1. Halaman Splash Screen

Halaman ini merupakan tampilan awal saat membuka aplikasi Monitoring.

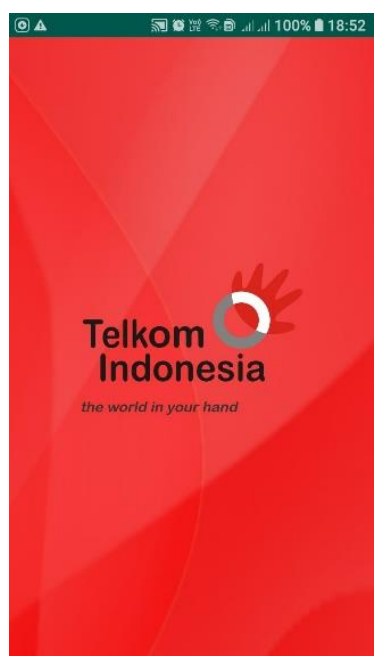

Gambar 5. Halaman Splash Screen

2. Halaman Login

Halaman ini digunakan untuk login aplikasi oleh pengguna aplikasi yang dalam hal ini diperuntukan bagi operator PT Telekomunikasi Indonesia. Tampilannya seperti Gambar 6. 


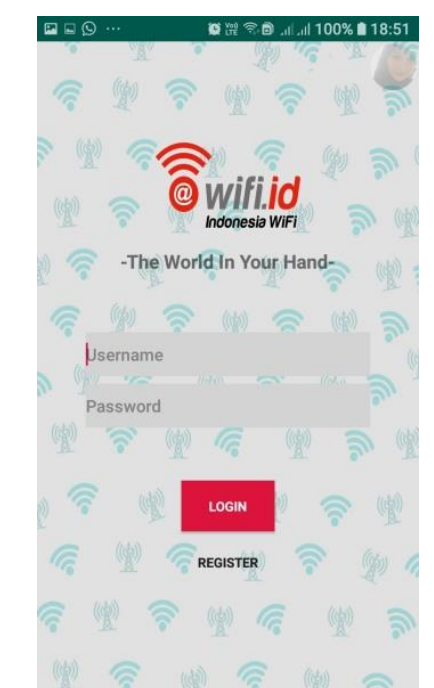

\section{Gambar 6. Halaman Login}

3. Halaman Register

Pada halaman ini digunakan untuk Register apabila pengguna aplikasi belum memiliki akun untuk login ke aplikasi. Tampilannya seperti Gambar 7.

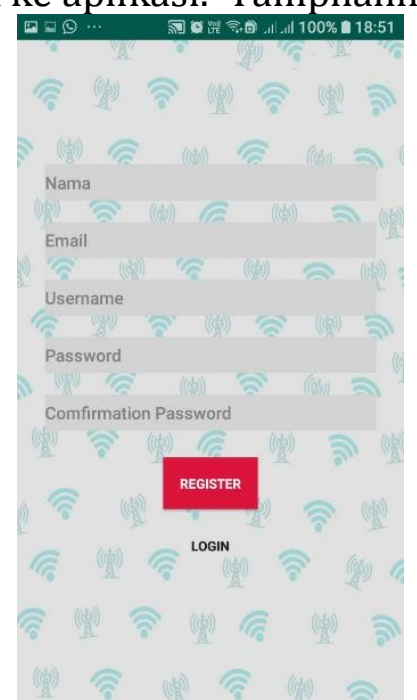

Gambar 7. Halaman Register

4. Halaman Menu Utama

Halaman merupakan halaman yang terdapat beberapa menu yang dapat digunakan oleh pengguna aplikasi. Menu yang terdapat pada tampilan ini yaitu menu List Wifi, History, Profil dan Keluar. Tampilannya seperti gambar 8. 


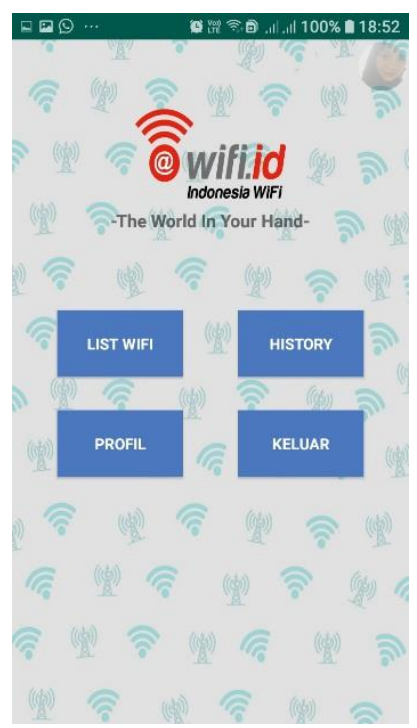

Gambar 8. Halaman Menu Utama

5. Halaman List Wifi

Pada halaman ini digunakan untuk melihat wifi yang sedang menyala disekitar pengguna aplikasi. Tampilannya seperti gambar 9 .

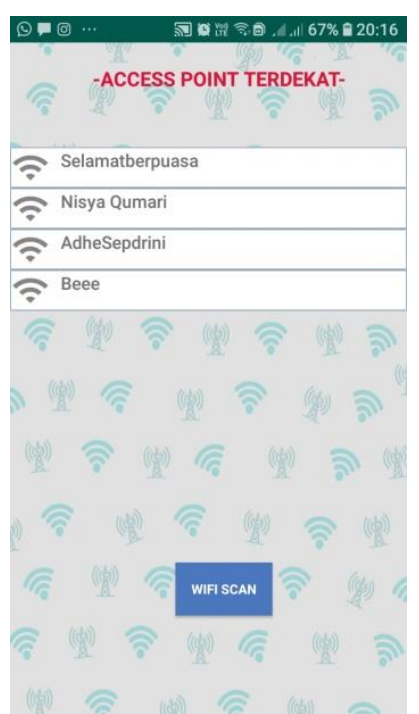

Gambar 9. Halaman List Wifi

6. Halaman Hasil Monitoring

Pada dua Halaman ini yang merupakan halaman yang menampilkan parameter yang ada pada Access Point (AP) yang telah berhasil dicek apabila menekan button ukur dan apabila ditekan button Bandwidth akan menapilkan tampilan seperti gambar yang ada di sebelah kanan. Pada gambar dibawah ini merupakan hasil pengukuran parameter pada Access Point (AP) "Selamatberpuasa”. 

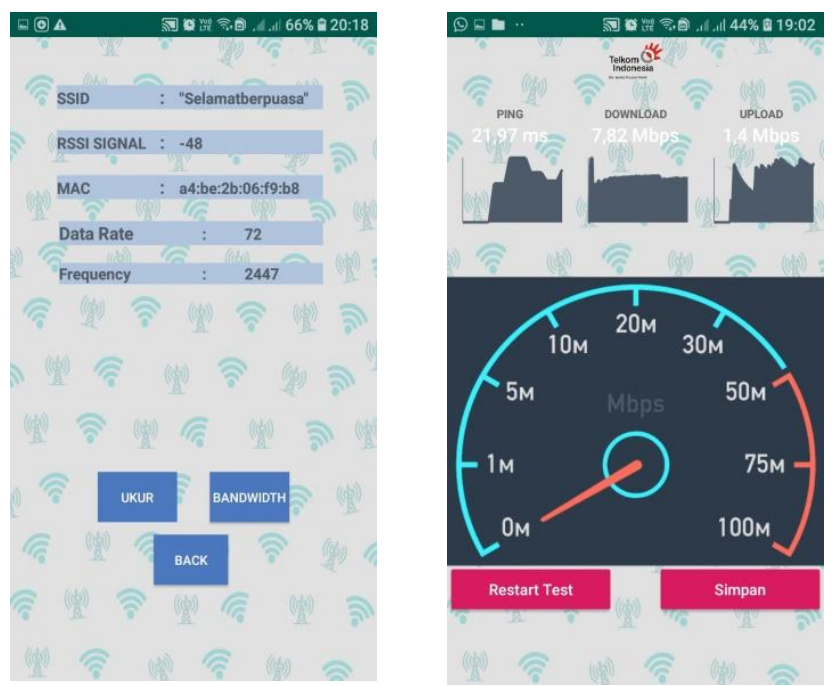

Gambar 10. Halaman Hasil Monitoring

7. Halaman History

Pada halaman ini digunakan untuk menapilkan riwayat dari hasil monitoring yang dilakukan oleh pengguna aplikasi. Seperti sebelumnya telah dilakukan pengukuran pada Access Point (AP) "Selamatberpuasa", maka hasil monitoring tersebut langsung masuk ke halaman History ini. Tampillannya seperti gambar 12 .

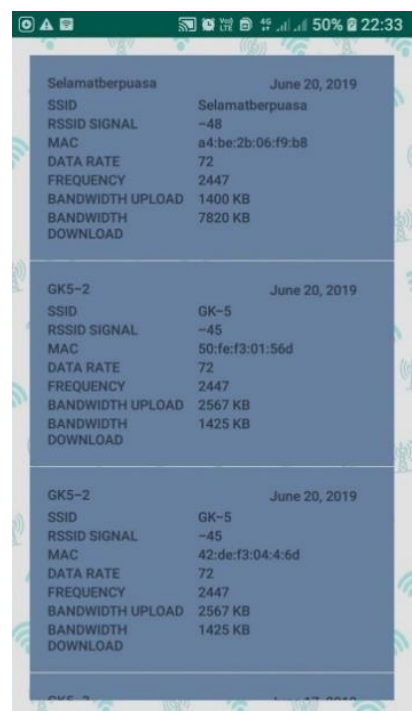

8. Halaman Profil

\section{Gambar 11. Halaman History}

Pada halaman ini menampilkan profil dari pengguna aplikasi, berisi berupa data yang telah disi oleh pengguna aplikasi saat melakukan proses register akun. Tampilannya seperti gambar 13 . 


\section{SIMPULAN}

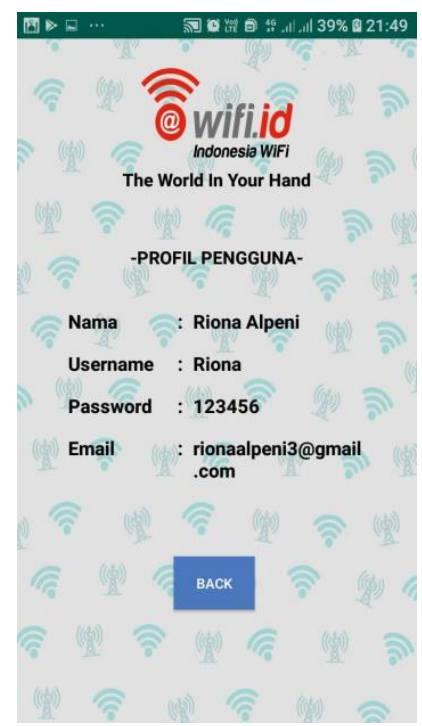

\section{Gambar 12. Halaman Profil}

Aplikasi Monitoring Wifi.id PT Telekomunikasi Indonesia ini merupakan aplikasi berbasis Android. Aplikasi ini digunakan untuk melakukan pengecekan parameter-parameter yang terdapat pada Access Point (AP). Adapun parameter yang dapat di ukur yaitu Bandwidth, Service Set Identifier (SSID) , Media Access Control Address (MAC Address), Received Signal Strength Indication (RSSI), Data Rate, dan Frekuensi Access Point (AP). Diharapkan agar dengan adanya aplikasi Monitoring Wifi.id berbasis andorid ini dapat mempermudah operator PT Telekomunikasi dalam melakukan pengecekan parameter yang pada Access Point (AP) sehingga PT telekomunikasi Indonesia dapat selalu memberikan pelayanan terbaiknya dan dapat memberikan kepuasan kepada pengguna layanan telekomunikasi dari PT Telekomuniaksi Indonesia.

\section{DAFTAR PUSTAKA}

[1] O. TONAPA, P. RAHMIATI, and D. KOMBA, "Analisis Performansi Konektifitas Pada Jaringan Wireless Broadband di Bandung," J. Elkomika, vol. 2, no. 2, pp. 162-170, 2017.

[2] W. Y. Pusvita and Y. Huda, "Analisis Kualitas Layanan Jaringan Internet Wifi.Id Menggunakan Parameter QOS ( Quality Of Service ) Westi Yulia Pusvita 1) , Yasdinul Huda 2) 2," vol. 7, no. 1, 2019.

[3] M. M. Nareswari and A. P. S. T, "Analisis Kepuasan Pemakai Layanan Wifi . Id Pada Wifi . Id Corner Di Kota Bandung Analysis User Satisfaction of Wifi . Id At Wifi . Id Corner in Bandung," vol. 3, no. 2, pp. 1041-1046, 2016.

[4] B. Folaimam, Rosihan, and A. Mubarak, "Implementasi Algoritma Dijkstra Untuk Penentuan Jalur Terpendek Pada Aplikasi Evakuasi Bencana Untuk Penyandang Disabilitas," J. Inform. dan Komput., vol. 2, no. 2, pp. 61-69, 2018.

[5] Yurindra. (2017). Software Engineering. Yogyakarta: Deepublish 